\title{
Recovery of metabolisable energy intake as portal net appearance of SCFA in sheep fed hay or concentrate diets
}

\author{
NB Kristensen, A Danfær, N Agergaard \\ National Institute of Animal Science, Dept Animal Physiology and Biochemistry, \\ PO Box 39, 8830 Tjele, Denmark
}

From studies on the rate of SCFA production in the gastrointestinal tract of ruminants it has been concluded that SCFA were able to supply most of the energy needed by the ruminant animal at least at maintenance. It has recently been found that only a minor fraction of $\mathrm{ME}$ (metabolisable energy) intake (16\%) can be accounted for by net appearance of SCFA across the rumen wall of sheep (Rémond et al, 1993, J Anim Sci, 71, 2529-2538). In cattle higher recoveries of $M E$ intake as portal net appearance of SCFA have been found (38-53\%) and the percentage of ME accounted for by net portal appearance of SCFA is influenced by stage of the animal and feed composition (Huntington, 1990, Reprod Nutr Develop, 30, 35-47). The aim of the present study was to measure the recovery of ME intake as net portal appearance of SCFA in sheep fed hay or concentrate diets.

Three Leicester ewes $(76 \pm 10 \mathrm{~kg} \mathrm{BW})$ were fitted with a flowprobe around the portal vein (16s, Transonic System Inc), portal vein and mesenteric artery catheters and a rumen cannula. The sheep were fed two different diets with an adaptation period to each diet of at least 21 days. The sheep were fed twice a day ( 7 and $15 \mathrm{~h}$ ) and had free access to water and mineral blocks. The hay diet contained $1.3 \mathrm{~kg} \mathrm{DM}$ (dry matter) with $10 \% \mathrm{CP}$ (crude protein) and a calculated energy content of 13 MJ ME. The concentrate diet contained $0.85 \mathrm{~kg}$ barley based concentrate DM (in percent :

Feed ME (MJ/d)

SCFA conc rumen (mmol/l)

Mol \% SCFA rumen (Ac : $\mathrm{Pr}: \mathrm{Bu}$ : Isobu)

Net portal appearance SCFA (mol/d)

Mol \% net portal appearance (Ac : $\mathrm{Pr}: \mathrm{Bu}:$ Isobu)

Net portal appearance SCFA (MJ/d)

Recovery of ME in individual SCFA (Ac : $\mathrm{Pr}: \mathrm{Bu}$ : Isobu)

Percent of ME recovered in SCFA

Different letters in different columns indicate significant $(\mathrm{P}<0.05)$ difference.

$\mathrm{Ac}$ : acetate ; $\mathrm{Pr}$ : propionate ; $\mathrm{Bu}$ : butyrate ; Isobu : isobutyrate barley 68 , soya meal 25 , molasses 2 , wheat bran 2 and minerals 3) and $0.85 \mathrm{~kg}$ barley straw DM, in total $1.7 \mathrm{~kg} \mathrm{DM}$ with $13 \% \mathrm{CP}$ and a calculated energy content of $17 \mathrm{MJ}$ ME.

Portal and arterial blood as well as rumen fluid were sampled for 24 hours. Portal blood flow was recorded continuously with a flowmeter connected to a computer. The SCFA content of blood and rumen fluid samples was measured by gas chromatography. Values are presented as $24 \mathrm{~h}$ means \pm SEM or integrated within $24 \mathrm{~h} \pm$ SEM (3 experiments per diet).

The concentrate diet was followed by an increased intake of $M E$, increased rumen SCFA concentration, decreased proportion of propionate (rumen and portal net appearance), increased proportion of butyrate (rumen and portal net appearance) and increased net portal appearance of SCFA (both in mol/d and $\mathrm{MJ} / \mathrm{d}$ ). But the recovery of $\mathrm{ME}$ intake as net portal appearance of SCFA was not different for the hay $(37 \pm 3 \%)$ and the concentrate $(36 \pm 2 \%)$ diet. These estimates are considerably higher than the estimates based on net appearance across the sheep rumen wall of about $16 \%$ of ME intake. This could indicate that absorption sites distal to the rumen (omasum and hind gut) are of major importance for SCFA absorption and contribute with the same amount of SCFA net appearance as the rumen.

\begin{tabular}{cc} 
Hay & Concentrate \\
\hline 13 & 17 \\
$81.7^{A} \pm 2.2$ & $95.3^{B} \pm 3.1$ \\
$68: 23: 9: 1$ & $69: 15: 15: 1$ \\
$4.27^{A} \pm 0.37$ & $5.39 \mathrm{~B} \pm 0.25$ \\
$67: 30: 3: 1$ & $72: 20: 6: 1$ \\
$4.77^{A} \pm 0.41$ & $5.97^{\mathrm{B}} \pm 0.28$ \\
$19: 15: 2: 1$ & $20: 10: 4: 1$ \\
$37^{\mathrm{A}} \pm 3$ & $36^{\mathrm{A}} \pm 2$
\end{tabular}

